\title{
Problems and prospects of current studies on the microecology of tongue coating
}

\author{
Juan $\mathrm{Ye}^{1,2}$, Xueting $\mathrm{Cai}^{1,2}$ and Peng $\mathrm{CaO}^{1,2^{*}}$
}

\begin{abstract}
Tongue diagnosis in traditional Chinese medicine (TCM) assesses the health by investigation of tongue coating. The science and technology of tongue coating analysis have become a significant issue for modernization of TCM. The relationship between microecology of tongue coating and TCM was relevant to the syndrome differentiation in TCM, such as the cold/hot syndrome may exhibit different specific microbiota patterns in the tongue coating. This article provides a review on the microbiota research of tongue coating.
\end{abstract}

\section{Introduction}

Tongue diagnosis, as a major means of observation and a characteristic feature of traditional Chinese medicine (TCM), discriminates physiological functions and pathological conditions by observing the changes in the tongue coating. In TCM theory, the tongue is an outer extension of pi (spleen) and wei (stomach), while the tongue coating is produced by wei qi through fumigation [1]. The tongue coating reflected the status of $p i$ and wei, corresponding to physiological and clinicopathological changes of inner parts of the body (Figure 1). It is the first information for TCM doctors to make a diagnosis and cannot be neglected. The status of zang and fu (internal organs), qi-xue (blood), and fluids of the human body, and the nature and severity of the disease, may be reflected in the tongue coating [2].

In Western medicine, the concepts of "geographic tongue" and "tongue colored regions" has been related to illness [3], indicating some advantages of tongue diagnosis (e.g., non-invasive and simple) [4]. Inspecting plays an important role in tongue diagnosis but usually deemed as the empirical judgments by TCM doctors using their naked eyes. A tongue diagnosis is affected by examination circumstances, e.g., light source, patient's posture, and doctor's condition, its objectivity and reproducibility has been questioned. Studies on the molecular basis of tongue

\footnotetext{
* Correspondence: pcao79@yahoo.com

${ }^{1}$ Jiangsu Branch of China Academy of Chinese Medical Sciences, Nanjing 210028, China

${ }^{2}$ Laboratory of Cellular and Molecular Biology, Jiangsu Province Institute of Traditional Chinese Medicine, Jiangsu, China
}

diagnosis may provide significant contributions toward personalized medicine [5].

The National Institutes of Health officially launched the Human Microbiome Project in 2007, designed to determine the common core microbiome among different individuals [6]. In 2010, the European Union carried out the Human Gut Microbiome Project [7]. The microecology, the inner microecosystem, an organic integrity consisting of natural microbiota, host, and environment are interdependent and interactive of the body influences physiology and pathology [8]. The inner microecosystem contains an intercrossing network structure, among different levels and different segments, and a dynamic balance that consists of material, energy, and information flow [8]. The microecological balance is formed in dynamic physiological combination during the long-term historical evolution process [8]. However, when microecological imbalance occurs, pathological conditions arise [9]. The microbial flora on the tongue coating form one of the major microbiota in the human body, and are at the forefront of the alimentary system $[10,11]$. The tongue shares considerable similarity with the gut in microbial diversity $[12,13]$. Not only the human gut microbiome, but also the characteristics and structures of microbiomes are involved in the human health status $[14,15]$. Patients with different diseases might exhibit different characteristics and structures of microbiome $[9,16,17]$.

\section{Recent advances}

Total bacterial count on the tongue coating and the content of lysozyme were decreased after cure of acute pancreatitis (AP) [18]. The microbiota imbalance on the 


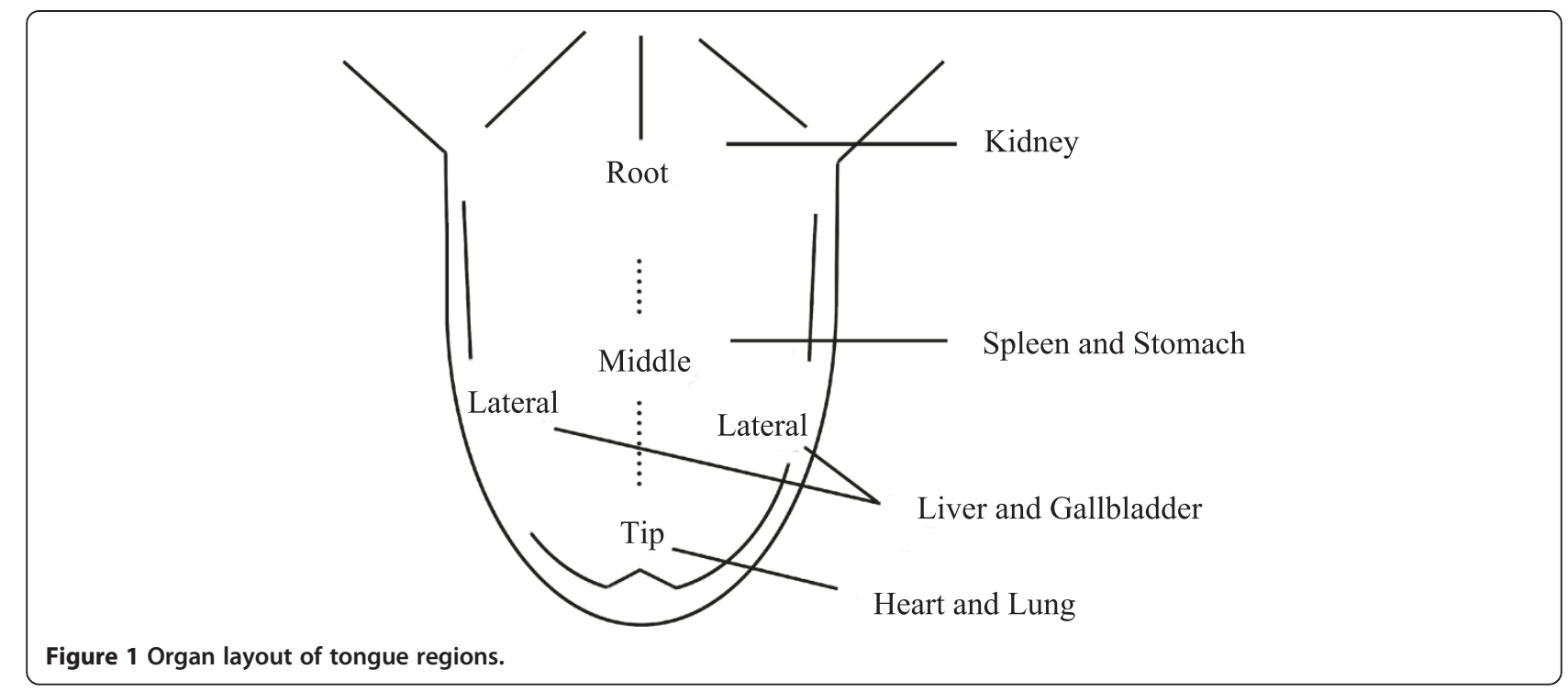

lingual surface was related to the changes in the tongue coating. AP patients had a thick tongue coating and increased in Gram-negative anaerobic bacilli [18]. Zhu et al. [19] prepared tongue coating smears for microscopic examination after Gram-staining to set the quantitative criteria for analyzing the microbiota on the tongue coating of patients with damp-heat syndrome. They discovered that the total bacterial count was higher in damp-heat syndrome's yellow-dense tongue coating than in the normal white-greasy coating. Another study [20] diagnosed patients suffering from diarrhea-predominant irritable bowel syndrome, through microscopic examination of tongue coating smears to be a $p i$ and wei's shi-re (damp-heat) syndrome. Denaturing gel gradient electrophoresis (DGGE) was increasingly used in tongue coating studies. Fei et al. [21] discovered high similarity in DGGE analysis among different samples from the patients with lung cancer, indicating that the type of tongue coating was similar in the composition of microbial flora. $16 \mathrm{~S}$ rRNA-DGGE was used to investigate the microbial changes in chronic gastritis patients' greasy tongue coating, and found a new species of bacteria closely associated with the generation of greasy tongue coating [22]. The new species has a nearest neighbor Moraxella catarrhalis with a similarity of $96.2 \%$. The microbial changes in the oral cavity could be one of the causes of the generation of greasy tongue coating. In addition, research on the relationship between TCM and tongue coating using the tongue coating rating scale found that a Jianpishenshi decoction changed the intestinal microecology and tongue coating of the patients with pi-xue (spleen-deficiency) syndrome [23].

\section{Research issues}

First, few modern experimental techniques 'have been employed by the studies of the microecology of tongue coating such as bacteria cultures and microscopic examination. Conventional bacteria cultures and microscopic examination of smears are inadequate to analyze large sizes of samples [24]. Second, the sample

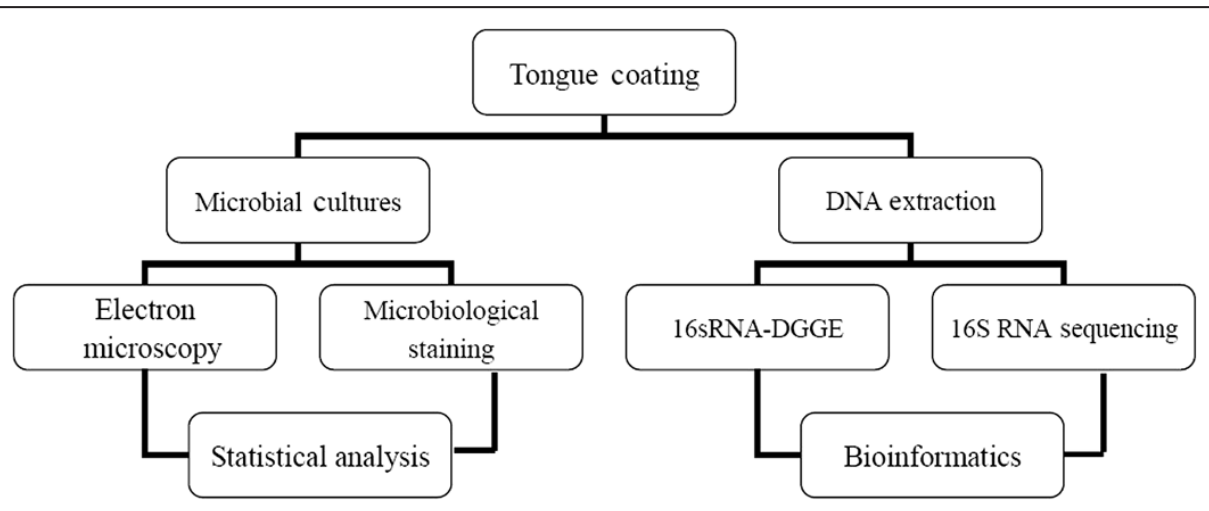

Figure 2 Outlook of current methodological approaches for tongue coating analyses regarding the relationship with microecology. 
collection was not systematic [25]. The lack of objective judgment of "zheng" makes eliminating individual differences and differences between TCM doctors difficult. The diseases of different internal organs would be reflected in different regions (Figure 1), such as the tongue tip for xin (heart) and fei (lung) that belong to upper-jiao, middle tongue for $p i$ and wei that belong to middle-jiao, tongue root for shen (kidney) that belongs to lower-jiao, and lateral tongue for gan (liver) and dan (gallbladder). It is necessary to establish a standard process for collecting tongue coating samples to ensure the comparability of samples collected from different patients.

\section{Prospects}

First, inclusion and exclusion criteria for sampling collection should be established. Second, non-culture-based bacteriological technology, like 16sRNA-DGGE [26], 2S-DGGE [27], RFLP-PCR [28], and RAPD-PCR [29], should be used for bacterial component analyses, and floral structural relation analyses, and flora network analysis (Figure 2).

Bai et al. [30] analyzed tongue-coating microbiomes and their relationships with tongue diagnosis, proposing a method of zheng discrimination before Kanawong et al. [31], by a machine learning algorithm with a color space set of features. Lo et al. [32] proposed standardization of zheng by determining the regions in which the samples were distributed on the tongue dorsa and fixing the sample collection region. Bai et al. [30] applied the next-generation sequencing methods to analyze tongue coating samples via bacterial 16sRNA V6 regions and analyzed the network of operational taxonomic units and microecology of zheng.

\section{Conclusions}

The status of qi-blood, cold or hot syndrome, and progress of some diseases are associated with the change in microbiome on the tongue surface.

\section{Consent}

Written informed consent was obtained from the patient's for the publication of this report and any accompanying images.

\footnotetext{
Abbreviations

TCM: Traditional Chinese medicine; AP: Acute pancreatitis; DGGE: Denaturing gel gradient electrophoresis.
}

\section{Competing interests}

All authors declare that they have no competing interests.

\section{Authors' contributions}

PC conceived and designed the study. JY, CX and PC wrote the manuscript. All authors read and approved the final version of the manuscript.

\section{Acknowledgement}

This study was supported by the National Basic Research Program of China (973 Program) - 2014CB542900 and a grant from the Jiangsu Province's Outstanding Leader Program of Traditional Chinese Medicine. The authors thank Pro. Jingqing Hu provide professional advice, review and confirm the manuscript in the revising period all along.

Received: 19 February 2013 Accepted: 28 February 2014

Published: 5 March 2014

\section{References}

1. DongYuang L: Dong-Yuan's Treatise on the Spleen \& Stomach: A Translation of the Pi Wei Lun. Boulder, Colorado: Blue Poppy Press, Printed at Johnson Printing; 2004

2. Wu J, Zhang $Y$, Bai J: Tongue area extraction in tongue diagnosis of traditional Chinese medicine. Conf Proc 2005, 5:4955-4957.

3. Zadik Y, Drucker S, Pallmon S: Migratory stomatitis (ectopic geographic tongue) on the floor of the mouth. J Am Acad Dermatol 2001, 65(2):459-460.

4. Anastasi JK, Currie $L M$, Kim GH: Understanding diagnostic reasoning in TCM practice: tongue diagnosis. Altern Ther Health Med 2009, 15(3):18-28.

5. Lu A, Jiang M, Zhang C, Chan K: An integrative approach of linking traditional Chinese medicine pattern classification and biomedicine diagnosis. J Ethnopharmacol 2012, 141:549-556.

6. Human Microbiome Project C: A framework for human microbiome research. Nature 2012, 486(7402):215-221.

7. Maccaferri S, Biagi E, Brigidi P: Metagenomics: key to human gut microbiota. Dig Dis 2011, 29(6):525-530.

8. Wang JH: Traditional Chinese medicine and the positive correlation with homeostatic evolution of human being: based on medical perspective. Chin J Integr Med 2012, 18(8):629-634.

9. Ahn J, Rashmi S, Zhiheng P, Christine D, Jing W, Jianxin S, James JG, Richard BH, Liying Y: Human gut microbiome and risk of colorectal cancer. J Natl Canc Inst 2013, 105(24):1907-1911.

10. Dewhirst FE, Chen T, Izard J, Paster BJ, Tanner AC, Yu WH, Lakshmanan A, Wade WG: The human oral microbiome. J Bacteriol 2010, 192(19):5002-5017.

11. Segata N, Haake SK, Mannon P, Lemon KP, Waldron L, Gevers D, Huttenhower C, Izard J: Composition of the adult digestive tract bacterial microbiome based on seven mouth surfaces, tonsils, throat and stool samples. Genome Biol 2012, 13(6):R42.

12. Bik EM, Eckburg PB, Gill SR, Nelson KE, Purdom EA, Francois F, Perez-Peraz G, Blaser MJ, Relman DA: Molecular analysis of the bacterial microbiota in the human stomach. Proc Natl Acad Sci USA 2006, 103(3):732-737.

13. Jakobsson HE, Jernberg C, Andersson AF, Sjolund-Karlsson M, Jansson JK, Engstrand $\mathrm{L}$ : Short-term antibiotic treatment has differing long-term impacts on the human throat and gut microbiome. PLoS One 2010, 5(3):e9836.

14. Turnbaugh PJ, Gordon J: The core gut microbiome, energy balance and obesity. J Physiol 2009, 587(Pt 17):4153-4158.

15. Avila M, Ojcius DM, Yilmaz O: The oral microbiota: living with a permanent guest. DNA Cell Biol 2009, 28(8):405-411.

16. Koren O, Omry K, Aymé S, Jenny F, Frida F, Jesse S, Valentina T, Carl JB, Rob K, Björn F, Ruth EL, Fredrik B: Human oral, gut, and plaque microbiota in patients with atherosclerosis. Proc Natl Acad Sci USA 2011, 108(Suppl 1):4592-4598.

17. Meurman JH: Oral microbiota and cancer. J Oral Microbiol 2010, 2.

18. Jing W, Caihua Z, Xiaorong X, Shouchun C: Changes of the microflora of tongue coating in acute pancreastitis patients. Chin J Microecol 1999, 11:159-162

19. Zhu LN, Huang LP, Lv JY, Que TS, Huang YQ, Ling JH, Yan M, Zhuo DT: Study on the tongue fur micro-ecosystem of damp-heat syndrome with microecology method. Guangxi Med J 2009, 31:480-482.

20. Jiang YF, Lao SX, Kuang ZY, Fu XY, Bian ZX: Preliminary studies on the microecosystem of fur lienteric enterovulnerability syndrome in the case of splenogastric dampness and heat. J Shaanxi Collage Tradition Chin Med 2005, 28:5-8.

21. Fei $X$, Dong RZ, Zheng $X$, Yi YD, Cai HD, Sheng YS, Chen YW, Zuhong L: Analysis of the microorganisms of bacterial communities among lung cancer patients with different TCM tongue coating. I Nanjing Xiaozhuang Univ 2010, 6:4-7. 
22. Li FF, Zhang J, Pang XY, Qian $P$, Cheng $H$, Wang YQ, Ye J, Fu JJ, Sun ZM: The oral microbial fingerprint on the greasy tongue coating of patients with chronic gastritis. Chin J Integr Med 2012, 32(10):1331-1335.

23. Lu L, Liu LC, Hai YJ, Yang JY: Study on the effect of Jianpishenshi decotion on the intestine microecology and change of tongue phase of patient. Chin J Microecol 2007, 19(5):439-441.

24. Tadashi W, Seizaburo AT, Shoji S, Toshikatsu K: Medical application of fuzzy theory to the diagnostic system of tongue inspection in traditional Chinese medicine. Conf Proc 1999, 8:22-25.

25. Liang $W N$, Li H, Li CD, Zhang LY: Clinic research of treating perimenopausal syndrome tongue demonstration changes by Chaihu Shugan decoction. China J Tradit Chin Med Pharmacy 2010, 25(2):201-203.

26. Huse $S M, Y e Y$, Zhou Y, Fodor AA: A core human microbiome as viewed through 16S rRNA sequence clusters. PLoS One 2012, 7:e34242.

27. Wang $\mathrm{S}, \mathrm{He} \mathrm{J}$ : Two-step denaturing gradient gel electrophoresis (2S-DGGE), a gel-based strategy to capture full-length $16 \mathrm{~S}$ rRNA gene sequences. Appl Microbiol Biotechnol 2012, 95(5):1305-1312.

28. Swiat A, Stepien E, Andres J, Dziatkowiak A: Use of polymerase chain reaction in medical diagnosis. Przegl Lek 1999, 56(11):723-734.

29. Feligini M, Panelli S, Buffoni JN, Bonacina C, Andrighetto C, Lombardi A: Identification of microbiota present on the surface of taleggio cheese using PCR-DGGE and RAPD-PCR. J Food Sci 2012, 77(11):M609-M615.

30. Jiang B, Liang $X$, Chen Y, Ma T, Liu L, Li J, Jiang R, Chen T, Zhang X, Li S: Integrating next-generation sequencing and traditional tongue diagnosis to determine tongue coating microbiome. Sci Rep 2012, 2:936.

31. Kanawong R, Obafemi-Ajayi T, Ma T, Xu D, Li S, Duan Y: Automated tongue feature extraction for ZHENG classification in traditional Chinese medicine. Evid Based Complement Alternat Med 2012, 2012:912852.

32. Lo LC, Chiang JY, Cheng TL, Shieh PS: Visual agreement analyses of traditional Chinese medicine: a multiple-dimensional scaling approach. Evid Based Complement Alternat Med 2012, 2012:516473.

doi:10.1186/1749-8546-9-9

Cite this article as: Ye et al.: Problems and prospects of current studies on the microecology of tongue coating. Chinese Medicine 2014 9:9.

\section{Submit your next manuscript to BioMed Central and take full advantage of:}

- Convenient online submission

- Thorough peer review

- No space constraints or color figure charges

- Immediate publication on acceptance

- Inclusion in PubMed, CAS, Scopus and Google Scholar

- Research which is freely available for redistribution 